\title{
Marine Structures
}

\section{Erkan Oterkus}

Department of Naval Architecture, Ocean and Marine Engineering, University of Strathclyde, Glasgow G4 0LZ, UK; erkan.oterkus@strath.ac.uk

Structural mechanics is an important field of engineering. The main goal of structural mechanics is to ensure that structures are safe and durable so that catastrophic situations can be prevented which could otherwise cause environmental pollution, financial loss, and the loss of lives. The usage of the structure and the conditions that the structure is subjected to require special treatment for the analysis. Specifically, marine structures are subjected to harsh environmental conditions due to marine environment which can cause several different damage mechanisms including fatigue and corrosion. This special issue on 'marine structures' considers a wide range of areas related to marine structures and provides a compilation of numerical and experimental studies related to research.

Qiu et al. [1] performed nonlinear finite element analysis in order to investigate the degradation of an offshore protective device by considering the effect of material corrosion. Gao and Oterkus [2] utilised a new computational technique, peridynamics, to study the state of damage to marine composites subjected to shock loading by performing fully coupled thermomechanical analysis. Plodpradit et al. [3] presented modal and coupled analyses of tripod-supported offshore wind turbines using X-SEA and FAST software packages. Hemmati and Oterkus [4] demonstrated a new model for offshore wind turbine systems equipped with a semi-active time-variant tuned mass damper by considering the nonlinear soil-pile interaction phenomenon and time-variant damage conditions. Ding et al. [5] studied towing operation methods, specifically for an offshore integrated meteorological mast to be used for offshore wind farms. Yu et al. [6] performed a failure analysis of topside facilities on oil/gas platforms in the Bohai Sea. Gao et al. [7] determined the cross-flow vortex-induced vibration (VIV) responses and hydrodynamic forces of a long flexible and low mass ratio pipe by performing laboratory tests. Liu and Yang [8] studied the characteristics of acoustic wave transmission in a metamaterial-type seawater piping system. Karambas and Samaras [9] developed an integrated coastal engineering numerical model which is capable of stimulating linear wave propagation, wave-induced circulation, sediment transport, and bed morphology evolution. Ameryoun et al. [10] performed stochastic modelling of bio-colonisation for the computation of stochastic hydrodynamic loading on jacket-type offshore structures. Finally, Chang [11] numerically investigated wave generation and vortex formation under the action of viscous fluid flows over a depression.

As a final remark, I hope the readers who are interested in marine structures will find this special issue useful for their studies.

Acknowledgments: I would like to thank the authors for their contributions to this special issue.

Conflicts of Interest: The authors declare no conflict of interest.

\section{References}

1. Qiu, A.; Han, X.; Qin, H.; Lin, W.; Tang, Y. Anti-Collision Assessment and Prediction Considering Material Corrosion on an Offshore Protective Device. J. Mar. Sci. Eng. 2017, 5, 37. [CrossRef]

2. Gao, Y.; Oterkus, S. Peridynamic Analysis of Marine Composites under Shock Loads by Considering Thermomechanical Coupling Effects. J. Mar. Sci. Eng. 2018, 6, 38. 
3. Plodpradit, P.; Dinh, V.N.; Kim, K.-D. Tripod-Supported Offshore Wind Turbines: Modal and Coupled Analysis and a Parametric Study Using X-SEA and FAST. J. Mar. Sci. Eng. 2019, 7, 181. [CrossRef]

4. Hemmati, A.; Oterkus, E. Semi-Active Structural Control of Offshore Wind Turbines Considering Damage Development. J. Mar. Sci. Eng. 2018, 6, 102. [CrossRef]

5. Ding, H.; Hu, R.; Le, C.; Zhang, P. Towing Operation Methods of Offshore Integrated Meteorological Mast for Offshore Wind Farms. J. Mar. Sci. Eng. 2019, 7, 100. [CrossRef]

6. Yu, S.; Zhang, D.; Yue, Q. Failure Analysis of Topside Facilities on Oil/Gas Platforms in the Bohai Sea. J. Mar. Sci. Eng. 2019, 7, 86. [CrossRef]

7. Gao, X.; Xu, Z.; Xu, W.; He, M. Cross-Flow Vortex-Induced Vibration (VIV) Responses and Hydrodynamic Forces of a Long Flexible and Low Mass Ratio Pipe. J. Mar. Sci. Eng. 2019, 7, 179. [CrossRef]

8. Liu, B.; Yang, L. Transmission of Low-Frequency Acoustic Waves in Seawater Piping Systems with Periodical and Adjustable Helmholtz Resonator. J. Mar. Sci. Eng. 2017, 5, 56.

9. Karambas, T.V.; Samaras, A.G. An Integrated Numerical Model for the Design of Coastal Protection Structures. J. Mar. Sci. Eng. 2017, 5, 50. [CrossRef]

10. Ameryoun, H.; Schoefs, F.; Barillé, L.; Thomas, Y. Stochastic Modeling of Forces on Jacket-Type Offshore Structures Colonized by Marine Growth. J. Mar. Sci. Eng. 2019, 7, 158. [CrossRef]

11. Chang, C.-H. Numerical Analyses of Wave Generation and Vortex Formation under the Action of Viscous Fluid Flows over a Depression. J. Mar. Sci. Eng. 2019, 7, 141. [CrossRef]

(C) 2019 by the author. Licensee MDPI, Basel, Switzerland. This article is an open access article distributed under the terms and conditions of the Creative Commons Attribution (CC BY) license (http://creativecommons.org/licenses/by/4.0/). 